\title{
To Continue To Teach Architecture Through the Myth of the "Guru" Is To Kiss Culture and Heritage Good-bye
}

\author{
MELANIE RICHARDSON and DEREK TROWELL \\ University of Sheffield \\ United Kingdom
}

\begin{abstract}
The view over most cities of haphazard urban sprawl, and the general dismal qualities of most modern architecture, seem irreconcilable with the fact that, before being let loose on our environment, Architects are incarcerated for 5 years or so in an Academic Institution.

Why is this?

It is our thesis that it is not necessarily the quality of teaching that is to blame, but rather the context. We believe that by organising studio project work in a way which addresses wider issues such as procurement, and an understanding of the role that other professionals inevitably play in the design process, a richer outcome is achievable.

We will explore this theme and propose some simple, but fundamental, changes to architectural education. We will discuss two projects devised by the authors with a view to addressing the perceived imbalance between the input of academics, and the output of professionals.
\end{abstract}

\section{INTRODUCTION}

The conventional role of the architect in 20th century society no longer exists. Yet this role is that which is generally still perpetrated by both Schools of Architecture and Schools of Planning alike.

The mythical role that our students are still encouraged to follow, remains both elitist, and unattainable, as it relates on an urban scale, to problem solving roles that generally speaking no longer exist. The role to which we refer is that of either the architect or the planner / urban designer, working in isolation and perhaps, more dangerously, without an understanding of their respective "counter-professionals".

This method of working in the world outside academia has led to a catalogue of urban disasters world-wide and too painful to list. These disasters range from the near total loss of our industrial heritage, to the arterial severance of the historic street patterns that were once the generators of our cities, by highway engineers. A classic example of the latter can be seen in the English Midland's city of Nottingham. A ring road has been carved around the inner city which savagely slices through a mediaeval street pattern leaving the outer edge of the city literally severed from it's commercial heart. This is surely an example of madness by an individual acting in isolation from the views and concerns of other professionals, collaboration with whom, might have lead to a more acceptable solution. This act of madness on a grand and irreversible scale is summed up perfectly by the architectural writer and historian, Sir Nikolaus Pevsner, who is said to have described Nottingham's Inner Ring Road as, "The ugliest street in Europe"

In his book, "The Buildings of England", Nottinghamshire Edition, he writes, "Nottingham has been subjected to a traffic scheme that has involved the destruction, of a number of good buildings and the disruption to no aesthetic advantage, of the old street pattern." 1

Developers and the public alike are beginning to realise that it is no longer acceptable to flatten large areas of land upon which stand redundant buildings for both financial, and social reasons, respectively. Architects are, as a consequence, increasingly having to work within constrictive urban constraints, beyond those which they are trained to address. It is becoming increasingly necessary to address this phenomena in the way in which we teach those to whom we will later entrust with our built environment.

We suggest that two critical areas warrant considerably greater academic input than they are at present given. These are:

\section{An input into the field of urban regeneration.}

The constraints imposed by the need to work within an extinct industrial framework, for example in an area where once vast industries such as shipbuilding, steel working or coal mining have disappeared demand skills and understanding which reach far beyond an ability to design and construct individual buildings. Buildings in areas such as this must have a context, a place in a wider framework. Such a framework might be a master plan, or a vision, it does not matter, as long as it exists. Too often we see redevelopment occurring within a framework that is little more than slicing up an area of land into building plots. This inevitably leads to an impoverished environment and one which recaptures 


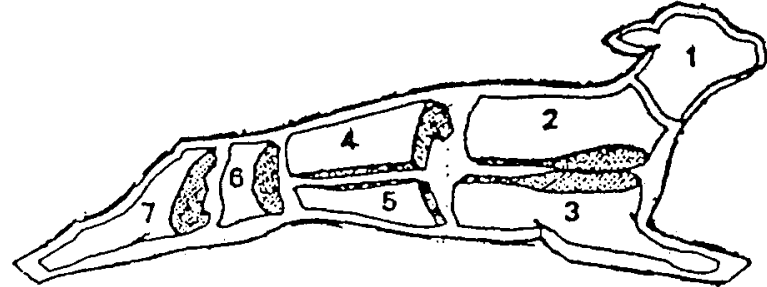

Figure 1. "For tastiest cuts read juiciest profits."

none of the richness of what it replaces.

Development in this fashion has as much to do with urban design as do the drawings we sometimes see in butchers shops identifying the way in which animals are sliced up in abattoirs at slaughter. For "tastiest cuts" read "juiciest profits".

Sheffield is a good example to look at in this respect. The "Lower Don Valley" on the edge of Sheffield was home to the largest steel making industry in Europe. In the space of around fifty years, economic pressures, and advances in manufacturing techniques in developing countries have lead to the almost total collapse of this industry and left a vast tract of land a deserted relic of a bygone age. The two grain maps of the Lower Don Valley reproduced below graphically illustrate this point.

The response to this decline has been to flatten large areas of land, with the total loss of many fine, but admittedly,

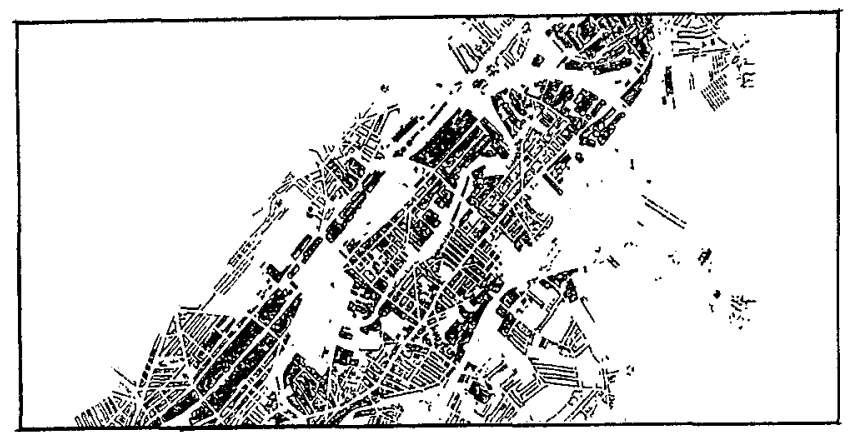

Figure 2. The Lower Don Valley, Sheffield. Grain map. 1924.

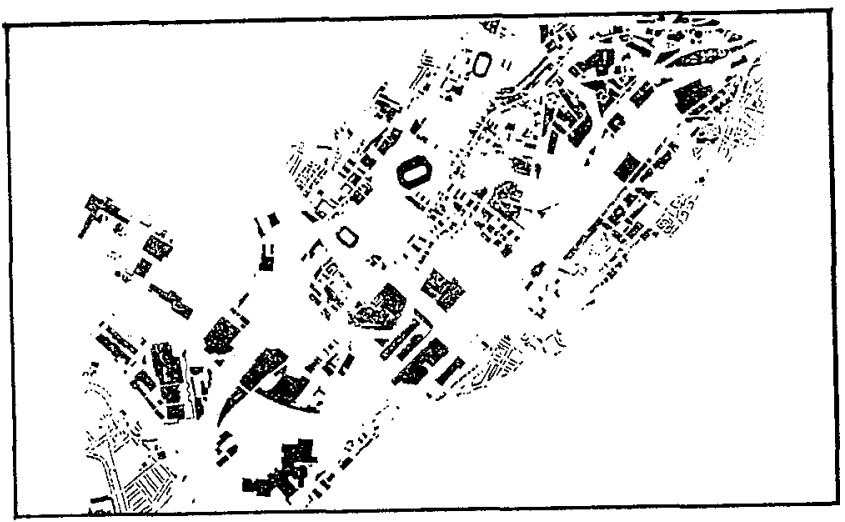

Figure 3. Lower Don Valley; Sheffield. Grain map 1993. The loss of a manufacturing industry is clearly shown. difficult to re - use, buildings. The tragedy is that the land is then redeveloped, not in a way which attempts to recapture, or even refer to, a historic framework or urban pattern, but in the "choicest cuts" fashion described above. Urban grain is unlikely to be a consideration.

\section{An input into understanding the problems associated with contemporary urban design within a historic urban settlement.}

This is necessary if we are to equip our students with the skills to address issues raised by population expansion and changing transportation patterns without destroying cultural and vernacular traditions. Such traditions must be understood if modern interventions are to make more than just totally pragmatic sense. The Nottingham ring road probably made pragmatic sense, but on any other level it is simply folly.

To illustrate this second critical issue we can look at the historic English market town of Bakewell, situated in the heart of The Peak District National Park.

For centuries the centre of Bakewell has been a meeting place for the regional agricultural community, and the base for a weekly cattle market, vital to the economic survival of both the county and the local community of Bakewell, whose inhabitants exist principally on an income associated with providing service industries associated with the market. The narrow streets of Bakewell can no longer cope with the larger vehicles associated with a livestock market in the twentieth century. It is proposed therefore to relocate the market on the edge of the historic centre with an income generated by the release of the valuable building land which was the site of the original market.

This is a real problem, the solution of which demands skills beyond those we conventionally teach our students. The solution must address the incremental development of the town, cultural and climatic considerations, local needs and heritage, as well as modern requirements for highways, space standards and commercial viability. It is not impossible to address all of these issues when we offer design projects to our students.

The plan shown over leaf is of the centre of Bakewell, and it clearly illustrates the tight urban grain of the settlement, with buildings generally fronting directly onto the pavement. There is little scope for road widening, which would in any case, be detrimental to the character of the town.

\section{THE PROBLEM TO ADDRESS}

Both the Lower Don Valley, and Bakewell town centre require visionary solutions that respect the past but which do not suffocate modern design.

We believe that it is desirable through education to explore these issues and will describe two projects, one relating to each of the above themes, which we ran with 5th Year Architecture students and 2nd Year Planning students, with a view to creating an awareness of what we believe to be the current key urban problems. 


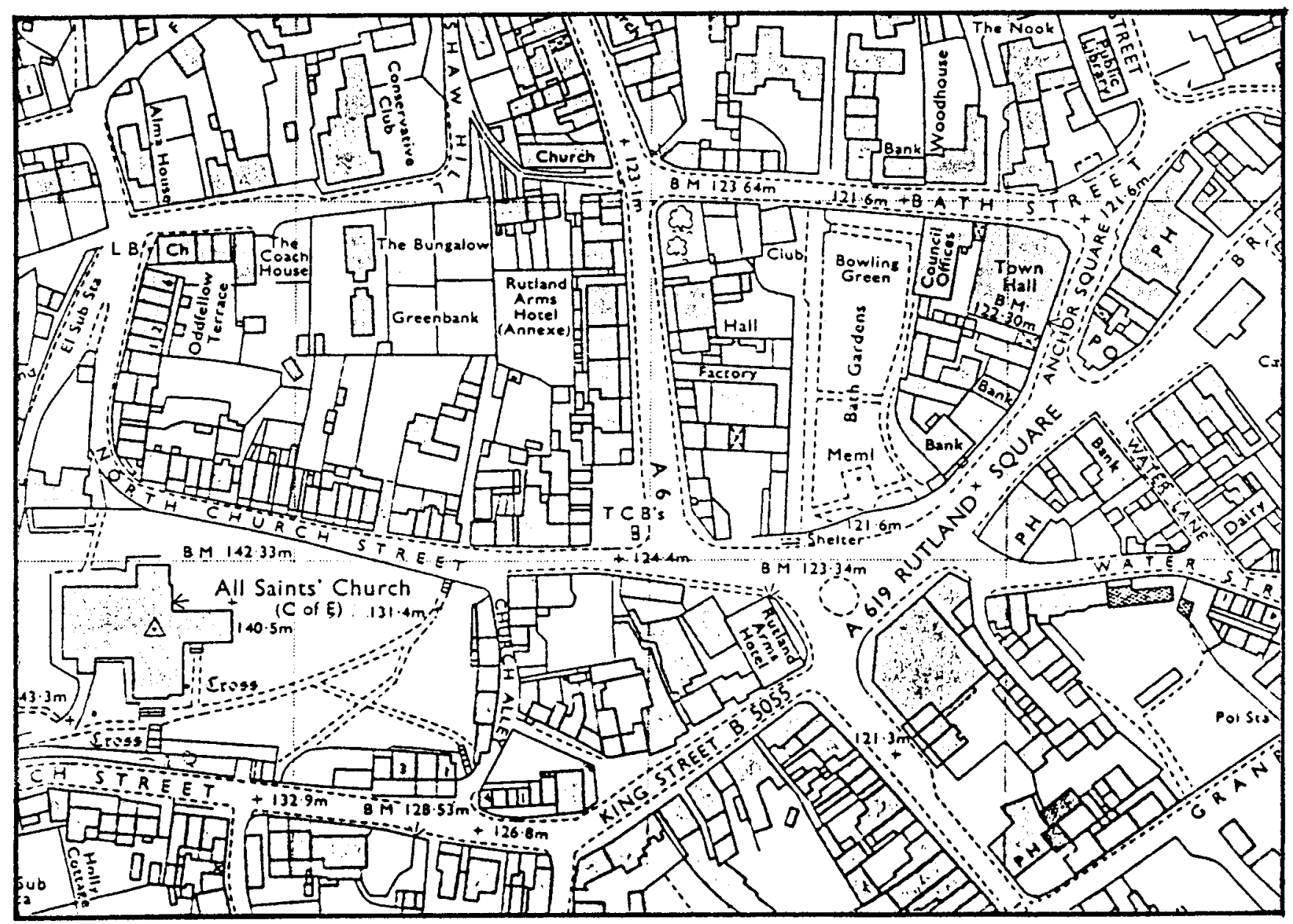

Figure 4. Bakewell Town centre plan. A tightly grained traditional English market town, struggling to cope with twentieth century living.

We will appraise the results of the projects and propose that a greater interaction between the professions is desirable if meaningful urban solutions are to be realised in the future. This interaction needs to be fostered at an early stage in schools of architecture. We can no longer sit back and allow our students to be taught by "Gurus", be they "design gurus", "planning - gurus" or "techno - gurus".

\section{THE TWO PROJECTS DESCRIBED}

\section{Urban Regeneration in The Lower Don Valley} 2 New Development within a Historic Framework

The two projects above were devised to explore our thesis. We will briefly describe the projects and assess the results.

\section{Urban Regeneration in The Lower Don Valley}

Our students of Architecture were asked to produce a detailed design for a building in The Lower Don Valley. However the key difference between this projects and every other project that the students had worked on in their previous five years at Architecture school, was that the brief offered, whilst highly detailed and structured, did not initially include a specific building type for design.

As an alternative approach students were asked to work in the following manner:

To initially carry out research in groups into various issues relevant to the area, such as, the history of the steel industry, transport infrastructure, grain map analysis and an appraisal of the current proposals for the area drawn up by Sheffield Development Corporation, SDC.

To present this research as a formal visual presentation and as a written, typed document. The various pieces of research undertaken were then compiled into a "text book" for reference purposes by all students.

To visit the site again and to consider an "alternative master plan " to that proposed by the SDC. Students were encouraged to present their work through an exploration of different presentation techniques such as videos, slides, taped interviews etc. At the reviews we made a deliberate decision to invite critics who were not architects, choosing instead other professionals, and members of the lay public. This is surprisingly rare in schools of architecture and as a result, student's work is reviewed from a very narrow viewpoint. We found that inviting non-architects to reviews had two key effects. Firstly, as one might expect, a more diverse range of issues was discussed, the norm being to dwell on detailed, and frequently highly subjective design 
issues. Secondly, students responded by producing much more convincing and rounded presentations of their work, and were both less defensive, and more responsive to criticism. The structure of the reviews in a series of stages, as in a real project, also helped in this respect, as at no time did the students feel that pressure of time had, "dug them into a hole."

To write a brief for a building, landscape or infrastructure proposal in the spirit of the master plan.

To develop a detailed proposal from this brief. Once again, this seemingly logical next step is not the norm. In a conventional project the students would probably be given a set brief for a building project. This not only renders their research work virtually useless, but denies the opportunity to learn the necessary skills of writing a concise and plausible brief. For example, students discovered that the possibilities available for intelligent regeneration went beyond conventional building. Some students proposed solutions which were very heavily dependant on infrastructure, sometimes in the form of conventional transportation proposals, but also in the form of landscape links. These latter students went on not to design buildings, but spaces between buildings, and produced highly successful projects which they later confessed they would not have had the courage or the imagination to develop had the project not been organised in the way that it was.

One of the most interesting proposals stemmed from an initial idea to flood large areas of the site to create a higher quality waterfront environment, rather than trying in vain to organise total redevelopment. This project shows an acute awareness of the financial inappropriateness of many proposals for massive redevelopment in the twentieth century, and proposes instead, a modest, mixed, and as a consequence, much more plausible scenario.

\section{New Development Within a Historic Framework}

This project was run with second year students of Town and Regional Planning. We adopted a real brief for the project, the proposal to relocate a mediaeval market in the historic

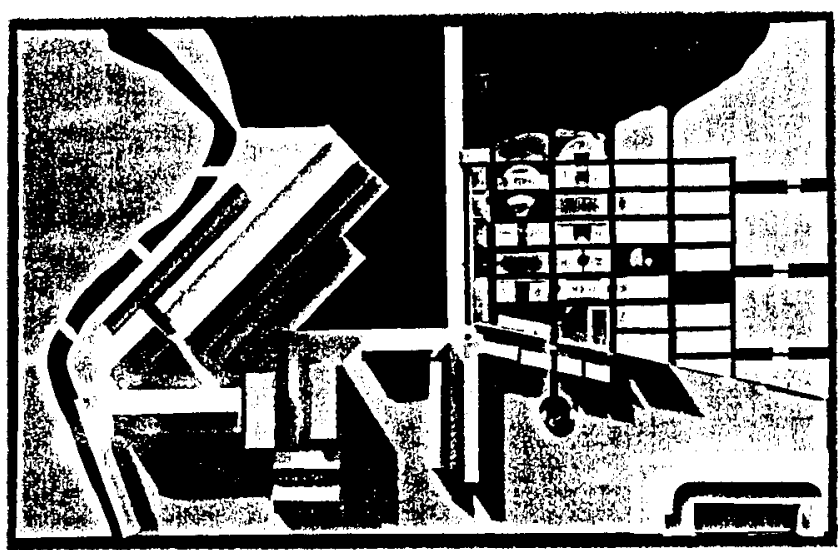

Figure 5. Photograph of a model of the design solution for a mixed waterfront development generated from the master plan and a brief devised by Heike Becker. town of Bakewell in the Peak District National Park, Derbyshire, described earlier.

As with the project set to Architecture students, we introduced critical elements of the design process into this project which astonishingly, are not covered else where in the curriculum. Briefly the agenda for the project was as follows:

Students where asked to carry out research, in groups into key aspects of the problem. Areas considered included the obvious, such as historical grain map analysis and a study of the local vernacular tradition. In addition, students talked to members of the local community and to local businesses to try and establish real needs. This is an obvious approach, but one that is rarely followed. It leads to a development proposal which is driven by local needs, and an understanding of a settlement pattern. A proposal developed along these simple lines and funded perhaps by complimentary development, is in contrast to the conventional. Typically a conventionally generated proposal would start from a profitable development idea which is then dressed up to be acceptable with a community "sop", typically low cost housing on the least valuable, and per se, least appropriate part of the site.

As this was the first design project these students had undertaken, we encouraged them to carefully consider presentation techniques, with a view to using the simplest means possible of getting an idea across. We introduced them to model making and other techniques such as collaging images in order to describe principles, as opposed to details.

In order to ensure a co-ordinated final presentation, we asked students to work in groups to produce a development strategy, which each group in turn presented, and the larger group then selected one project to develop in detail by a democratic vote. This group was then given the responsibility to co-ordinate the final presentation. They proposed a format, and as other groups worked up key areas, ensured compliance with the overall strategy to ensure that the final proposition was a coherent overall strategy, rather than a set of loosely related ideas.

The co-ordinating group, which we called "BOSS", asked for parcels of information each week either in drawn or model form, and text on disk to a standard format.

As with the previous project, we encouraged participation from a diverse range of critics, including students of both Architecture and Town and Regional Planning, and the organisers of the real project, The Peak Park Joint Planning Board, PPJPB. Reviews were held alternatively in the studio as tutorial sessions, and formally in public, at the offices of the PPJPB.

The final presentation was made to the full Planning Committee of PPJPB, and it is a measure of the success of the project that the committee felt that the document prepared by students, who had never undertaken any design work before, was a better solution than any of those received from professionals! The key difference was perceived by PPJPB to be that the students work was developed from an understanding of the fabric of Bakewell, and the needs of local 
people. This allowed the development of a framework around which a viable economic proposition was formed. Other proposals offered tended to be developed in the reverse order to this process. It is our view that a further reason for the success of the project was the elimination of competitive work at an early stage, using instead, collaborative working methods to refine the proposal and to eliminate the fear of failure from the students psyches.

\section{RESULTS AND CONCLUSIONS}

In both projects the quantity and quality of the students' work was encouraging. This assertion is somewhat subjective inevitably, however invitations to exhibit the work of both projects publicly, in the offices of the PPJPB, and The "Cutlers' Hall" in Sheffield respectively, lend credence to this view. Feedback from participants, critics and visitors to the exhibitions alike, was encouraging. This made the students feel that their work had real value and worth. One of the students undertaking the Lower Don Valley project received an actual commission for her proposal which may yet come to fruition.

The teaching techniques we adopted for these two projects and which to an extent we are putting forward to this conference as a model, do not propose anything radical. None of the working methods we adopted were expensive, or involved additional resources. In fact the teaching load in both cases was considerably reduced by achieving a more active participation from the students themselves.

In summary we believe that consideration should be given to the following issues when planning teaching projects in order to better prepare students for the changing nature of our world and the environmental problems they will face, on completion of their studies;

The need to offer briefs which are in themselves stretching and demand greater input from the students themselves. Contrary to the perception of "the Guru', students prefer to work on projects which are "real".
The need to encourage an element of group work in projects. We have found that a combination of competitive working, and collaborative working, consistently produces better results.

Where possible, assigning a group of students the task of documenting a project fosters collaborative working and reduces teaching loads.

Structuring project work into a number of clearly identifiable stages reduces the fear of failure, and has positive effects on the amount of exploration and the degree of "risk" students are prepared to undertake in order to arrive at the best, not the most eclectic, solution.

Working with other professionals, and a variety of critics, not necessarily from the academic world, produces more sophisticated solutions and has a positive effect on presentation techniques.

In final conclusion it is our thesis that the introduction of the element missing from the approach adopted by the "Guru" which we will call "reality", into project work does not in any way stifle creativity, but rather, it positively fosters it.

\section{REFERENCES}

The Buildings of England. Nottinghamshire. Nikolaus Pevsner. Second Edition, revised by Elizabeth Williamson. Penguin Books. pp 38

\section{ACKNOWLEDGEMENTS}

The authors would like to acknowledge the work of the following:

Peak Park Joint Planning Board.

John Keeley

Bryan Thompson

John Sewell

Sheffield Development Corporation.

John Keyworth

Sheffield University.

Students from year five, School of Architectural Studies, 1994, and year two, Department of Town and Regional Planning, 1994. 